\section{JURNAL ABDIMAS

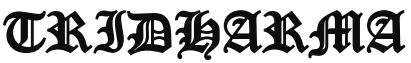

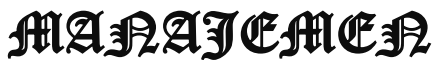

P-ISSN 2615-6849, E-ISSN 2716-070X

Jurnal ABDIMAS Vol. 1,No.2, Mei 2020,Hal(33-41)

@Prodi Manajemen Fakultas Ekonomi Universitas Pamulang

Email: abdimasjurnal.unpam@gmail.com Telp: (021) 741-2566

\title{
PENYULUHAN PERANAN SDM YANG POTENSIAL TERHADAP KEMAJUAN PERUSAHAAN DI PT SEJATI GRUP
}

\author{
Nurwita, Windy Agustina, Wahadi Siamto, R.Roro Metarini, Muhammad Gandung \\ Dosen Ekonomi Fakultas Ekonomi Universitas Pamulang \\ Email : Dosen01917@unpam.ac.id ,dosen01579@unpam.ac.id , \\ Dosen01458@unpam.ac.id, dosen00945@unpam.ac.id, dosen02020@unpam.ac.id
}

\begin{abstract}
ABSTRAK
Pengabdian ini berjudulPenyuluhan Peranan SDM( Sumber Daya Manusia) yangPotensial Terhadap Kemajuan Perusahaan di PT Sejati Grup.Tujuan pengabdian ini adalah untuk meningkatkan sumber Daya Manusia yang bekerja pada PT Sejati Grup dan mengetahui pengaruh SDM yang potensial terhadap Kemajuan Perusahaan jika memiliki karyawan yang sudah memiliki kemampuan potensial di dalam bidang pekerjaan nya.

- Adapun metode yang dilakukan dalam PKM ini adalah Presentation dengan memberikan presentasi materi yang berkaitan dengan Penyuluhan SDM yang potensial terhadap kemajuan perusahaan.Metode Discuss dengan cara memberikan kesempatan kepada mitra memberikan pertanyaan-pertanyaan yang berkaitan dengan tema PKM, metode Case dengan cara memberikan informasi terkait dengan kasus ,dan metode Evaluation dengan cara melakukan evaluasi terhadap apa yang sudah dilakukan oleh pihak mitra dan memberikan solusi apa yang akan dilakukan jika telah mengetahui bagaimana sudah mengetahui sumber daya manusia potensial dan dampak nya terhadap kemajuan Perusahaan setelah melakukan Penyuluhan PKM yang diadakan di PT Sejati Grup.

Kesimpulan dari pengabdian ini adalah Kegiatan PKM telah dilaksanakan dengan lancar dan baik serta telah memberikan pengetahuan dan keterampilan dalam bidang SDM untuk Kemajuan Perusahaan .Maka dapat disimpulkan bahwa manajemen SDM merupakan suatu proses yang meliputi serangkaian tindakan, dimana unsur-unsur dan fungsi- fungsi manajemen dipekerjakan se-efisien dan efektif mungkin dengan bantuan Karyawan sebagai Sumber Daya Manusia yang bertujuan untuk mencapai goals dan sasaran yang telah ditentukan sesuai dengan kebutuhan akan adanya kemajuan perusahaan serta berdasarkan atau melebihi standar kompetensi kerja yang telah ditetapkan mulai dari input, proses, sampai pada out- put nya.

Harapannya agar dapat menjadikan sumber informasi yang positif dan diunakan sebagai bahan, sumbangan pikiran, serta saran yang dapat membantu PT Sejati Grop menerapkan operasinya, baik secara langsung maupun tidak langsung yang berkaitan dengan Sumber Daya Manusia yang Potensial terhadap Kemajuan Perusahaan.
\end{abstract}

\section{Kata Kunci: Peranan SDM yang Potensial, Kemajuan Perusahaan}

\begin{abstract}
ABSTRAC
This dedication is titled Counseling the Role of Human Resources (Human Resources) which is Potential Towards Company Progress at PT Sejati Group The purpose of this service is to improve the Human Resources who work at PT Sejati Group and find out the potential influence of HR on Company Progress if it has employees who already have potential abilities in their field of work.
\end{abstract}




\section{JURNAL ABDIMAS

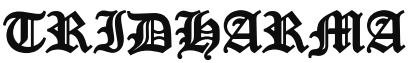

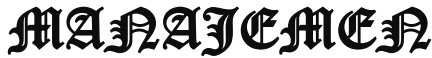

P-ISSN 2615-6849, E-ISSN 2716-070X

Jurnal ABDIMAS Vol. 1,No.2, Mei 2020,Hal(33-41)

@ Prodi Manajemen Fakultas Ekonomi Universitas Pamulang

Email: abdimasjurnal.unpam@ gmail.com Telp: (021) 741-2566

The method used in this PKM is a presentation by giving presentation material related to human resource education that is potential for the progress of the company. The Discuss method by providing an opportunity for partners to give questions related to the theme of PKM, the Case method by providing information related to the case, and the Evaluation method by evaluating what has been done by the partners and providing solutions to what will be done if you already know how to already know the potential human resources and their impact on the progress of the Company after conducting PKM Counseling held at PT SejatiGroup.

The conclusion of this dedication is that PKM activities have been carried out smoothly and well and have provided knowledge and skills in the field of HR for Company Progress. So it can be concluded that HR management is a process that includes a series of actions, where management elements and functions are employed as efficiently and effectively as possible with the help of Employees as Human Resources who aim to achieve the goals and targets that have been determined in accordance with the needs the progress of the company and based on or exceeds the work competency standards that have been set starting from the input, process, until the output.

The hope is to be able to make a positive source of information and use it as material, thought contribution, and advice that can help PT Sejati Grop implement its operations, both directly and indirectly related to Human Resources that are Potential for Company Progress.

\section{Keywords: The Role of Potential HR, Company Progress.}

\section{PENDAHULUAN}

Didirikan sejak 1986, PT. SEJATI GROUP adalah perusahaan yang terdiversifikasi yang bergerak di bidang distributor, perdagangan umum, pemasok, kontraktor, manufaktur offset \& percetakan dan bisnis jasa seperti; otomotif layanan satu atap, yang dikenal sebagai SLT (singkatan dari 'Sejati Layanan Terpadu' dan juga berisi filosofi bisnis kami yaitu 'Layanan Kenyamanan dan Kepercayaan') dengan slogan 'Keinginan Akan Melakukan Sejati Teknologi berpengalaman sebagai pemasok peralatan untuk agen militer dan sektor swasta seperti: Homeland Security, C4I, Sistem Intelijen, Kendaraan Udara Tak Berawak (UAV), Sistem Pengawasan, Sistem Pengamatan, Elektro-optik Lanjut, Solusi Kontrol, Sistem Komunikasi, Senjata Sistem, dan banyak perangkat lain sesuai dengan standar militer dan dirancang khusus untuk keperluan militer, intelijen, solusi pertahanan terpadu dan sipil sehingga permasalahannya adalah market segmen nya adalah yang mengantongi ijin dalam hal persenjataan di Indonesia
R2RSimply Irresistible Cafe 'Race 2 Run (R2R) Resto \& Cafe menghadirkan kreativitas berani bahan-bahan berkualitas segar, hidangan beraroma, dan bumbu khas Asia-Barat yang luar biasa untuk memberikan godaan rasa terbaik. Rasakan suasana yang kuat dari otomotif yang sporty dipadukan dengan pemandangan paling romantis dari Garden Veranda kami. Staf kami yang terampil dan penuh perhatian sangat terbiasa dengan pengalaman emosional tamu-tamu spektakuler kami. Di mana Anda akan selalu berharap untuk datang dan dimanjakan dengan gaya layanan yang lengkap.

SLT berpengalaman dalam layanan satu atap otomotif seperti: bensin, garasi (perbaikan mesin, pemeliharaan, suku cadang, aksesoris, dll), Gaya Otomatis SLT (salon mobil, pencucian mobil otomatis dan juga pencucian mobil manual), Resto \& Cafe dan banyak lagi fasilitas lain yang Anda akan menemukan suasana kombinasi antara rekreasi, santai dan layanan lainnya. .

Mencari layanan katering premium untuk acara Anda? PT Sejati Group 


\section{JURNAL ABDIMAS

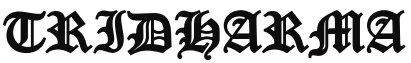

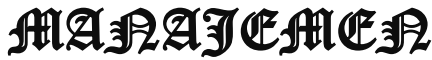

P-ISSN 2615-6849, E-ISSN 2716-070X

Jurnal ABDIMAS Vol. 1,No.2, Mei 2020,Hal(33-41)

@ Prodi Manajemen Fakultas Ekonomi Universitas Pamulang

Email: abdimasjurnal.unpam@gmail.com Telp: (021) 741-2566
Memperkenalkan LEVINA CATERING sebagai solusi terbaik Anda, yang dirancang untuk menjawab meningkatnya permintaan layanan katering premium di Jakarta. Selama lebih dari 30 tahun, kami berkomitmen untuk membawa semua acara di luar harapan klien kami, dan telah menjadi kontributor besar bagi pertumbuhan portofolio klien.Dalam segi produksi ada R2RSimply Irresistible Cafe 'Race 2 Run (R2R) Resto \& Cafe dan dalam segi manajemen yaitu sumber daya manusia

Indonesia memiliki modal yang cukup baik untuk menerapkan industri 4.0. Ada dua hal yang mendukung pengembangan industri di era digital, yaitu pasar yang besar dan jumlah SDM yang produktif seiring dengan bonus demografi.

Namun ketersediaan tenaga kerja juga harus selaras dengan kebutuhan pasar kerja itu sendiri, demikian diungkapkan oleh Bapak Khairul Anwar, Sekretaris Jenderal Kementerian Tenaga Kerja, pada acara Jumpa Pers Akhir Tahun yang dilaksanakan pada tanggal 28 Desember 2018

Seiring dengan revolusi industri 4.0 dan teknologi digital, persaingan bisnis dan pembangunan yang semula bertumpu pada pemanfaatan sumber daya alam akan bergeser pada penguasaan teknologi informasi dan kompetensi angkatan kerja. Di sinilah pentingnya investasi SDM. Sumber daya alam akan habis dieksploitasi dan melahirkan problem lingkungan. Tidak demikian dengan investasi SDM yang tak terbatas dan terus dinamis.

Saat ini Indonesia dihadapkan pada SDM angkatan kerja yang $58.76 \%$ adalah lulusan SD-SMP, serta problem mismatch mencapai $63 \%$. Untuk itu, diperlukan suatu intervensi dalam pembangunan SDM agar skill dan kompetensi angkatan kerja Indonesia mampu bersaing. Salah satu cara untuk meningkatkan kompetensi angkatan kerja adalah dengan pelatihan vokasi.

Kemnaker telah melakukan beberapa terobosan terkait dengan pelatihan vokasi tersebut. Yaitu dengan masifikasi pelatihan di Balai Latihan Kerja (BLK), pemagangan terstruktur, dan sertifikasi uji kompetensi.

Masifikasi pelatihan di BLK dilakukan dengan memberikan triple skilling yang meliputi skilling, up-skilling, dan re-skilling. Skilling dilakukan untuk angkatan kerja yang ingin mendapatkan keterampilan, up-skilling untuk pekerja yang ingin meningkatkan keterampilan, serta re-skilling untuk pekerja yang ingin mendapatkan keterampilan baru. Secara kumulatif, dari tahun 2015-Oktober 2018 peserta pelatihan BLK mencapai 383.132 orang. Pada tahun 2019 secara akumulasi jumlahnya naik menjadi 660.476 orang.

Untuk pemagangan, secara akumulasi sejak tahun 2015 hingga Oktober 2018 mencapai 149.064 orang. Pada 2019, secara akumulasi jumlahnya naik menjadi 360.864. Adapun peserta sertifikasi sejak 2015 hingga Oktober 2018 mencapai 1.349.559 orang, tahun 2019 secara akumulasi menjadi 1.875 .748 orang. Untuk mendekatkan akses pelatihan vokasi kepada masyarakat, pemerintah juga membangun BLK Komunitas. Tahun 2017 dengan 50 BLK Komunitas, 201875 BLK Komunitas. Tahun 2019 naik menjadi 1.000 BLK Komunitas. Tiap BLK Komunitas tiap tahunnya ditargetkan memberikan pelatihan kepada 100 orang.

Sementara untuk calon pekerja migran, Kemnaker juga akan memberikan pelatihan pada Balai Latihan Kerja Luar Negeri (BLKLN), yang pada 2019 ditargetkan memberikan pelatihan kepada 100 ribu calon pekerja migran.

Prioritas pembangunan SDM juga dimaksudkan dalam rangka menyelamatkan bonus demografi yang akan dialami Indonesia yang puncaknya terjadi pada tahun 2025-2030, di mana $70 \%$ penduduk Indonesia adalah usia produktif.

Hasil penelitian McKinsey Global Insitute menyebutkan bahwa Indonesia akan menjadi negara ekonomi terbesar ke-7 di dunia pada tahun 2030, naik dari peringkat 


\section{JURNAL ABDIMAS

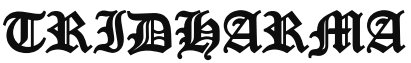

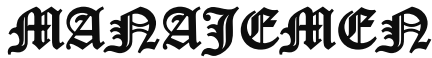

P-ISSN 2615-6849, E-ISSN 2716-070X

Jurnal ABDIMAS Vol. 1,No.2, Mei 2020,Hal(33-41)

@Prodi Manajemen Fakultas Ekonomi Universitas Pamulang

Email: abdimasjurnal.unpam@ gmail.com Telp: (021) 741-2566 ke-16 saat ini. Namun hal tersebut membutuhkan peningkatan produktivitas untuk memenuhi target pertumbuhan.

Indonesia mengalami pertumbuhan ekonomi yang cepat sebagai akibat dari kombinasi konsumsi domestik dan pertumbuhan produktivitas. Pada tahun 2030 Indonesia akan menjadi negara dengan ekonomi terbesar ke-7 di dunia, melampaui Jerman dan Inggris.

Kualitas SDM yang mumpuni dan terampil perlu dipersiapkan dalam menghadapi tidak hanya Revolusi Industri 4.0, namun juga peluang di tahun 2030 tersebut. Salah satu cara yaitu dengan adanya pelatihan vokasi (vocational training).

Pelatihan vokasi perlu mendapat perhatian penting karena memiliki kelenturan dalam mendorong perubahan skills di masyarakat. Akses seluas-luasnya yang diberikan pemerintah untuk tenaga kerja atau pencari kerja mengikuti pelatihan baik di Balai Latihan Kerja (BLK), industri, atau program magang diharapkan bisa mempersiapkan tenaga kerja masuk ke pasar kerja dan berwirausaha.

Semoga keberadaan pelatihan vokasi antara lain melalui BLK mampu memberikan kontribusi positif bagi pengembangan SDM Indonesia. Lulusan BLK diharapkan mampu bersaing menghadapi Revolusi Industri 4.0 ini, dan menjawab peluang Indonesia sebagai salah satu negara dengan ekonomi terbesar di dunia satu dekade lagi sehingga di adakan Pkm yang berjudul "Penyuluhan Peranan SDM yang Potensial Terhadap Kemajuan Perusahaan di PT Sejati Grup"

\section{RUMUSAN MASALAH}

Melihat dari permasalahan diatas, maka adapun rumusan masalah dalam kegiatan PKM ini adala sebagai berikut:

1. Bagaimana menentukan Sumber Daya Manusia yang Potensial yaitu pegawai yang tepat dengan keahlian sesuai bidang pada PT Sejati Grup ?

2. BagaimanaUsaha meningkatkan Kemajuan Perusahaan PT Sejati Grop khususnya dalam bidang Sumber Daya Manusia pada PT Sejati Grop?

3. Apa yang harus dilakukan oleh PT Sejati Grup dalam memaksimalkan Sumber Daya Manusia agar lebih ahli dan potensial dalam bidang nya agar mancapai keberhasilan perusahaan dalam kemajuan PT Sejati Grop?

\section{TUJUAN PELAKSANAAN}

Adapun tujuan dari PKM ini adalah sebagai berikut:

1. Untuk Mengetahui Bagaimana menentukan Sumber Daya Manusia yang Potensial yaitu pegawai yang tepat dengan keahlian di bidangnya pada PT Sejati Grop ?

2. Untuk Mengetahui Bagaimana Usaha meningkatkan Kemajuan Perusahaan PT Sejati Grop khususnya dalam bidang Sumber Daya Manusia pada PT Sejati Grop?

3. Untuk Mengetahui Apa yang harus dilakukan oleh PT Sejati Grup dalam memaksimalkan Sumber Daya Manusia agar lebih ahli dan potensial dalam bidang nya agar mancapai keberhasilan perusahaan dalam kemajuan PT Sejati Grop?

\section{TINJAUAN PUSTAKA}

1. Manajemen Sumber Daya Manusia Manajemen Sumber Daya Manusia adalah perencanaan, pengorganisasian, pengarahan dan pengawasan kegiatan kegiatan, pengadaan, pengembangan, pemberian kompensasi, pengintegrasian, pemeliharaan dan pelepasan sumber daya manusia agar tercapai berbagai tujuan individu, organisasi, dan masyarakat. (Flipo, 1989)

Manajemen Sumber Daya Manusia adalah sebagai penarikan, seleksi, pengembangan, penggunaan dan pemeliharaan sumber daya manusia oleh organisasi. (French dalam Soekidjo, 1991)

Manajemen Sumber Daya Manusia adalah suatu proses menangani berbagai masalah pada ruang lingkup karyawan, buruh, manajer dan tenaga kerja lainnya untuk dapat menunjang aktifitas organisasi atau 


\section{JURNAL ABDIMAS

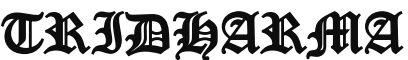

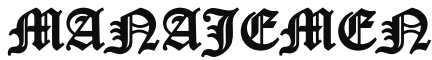

P-ISSN 2615-6849, E-ISSN 2716-070X

Jurnal ABDIMAS Vol. 1,No.2, Mei 2020,Hal(33-41)

@Prodi Manajemen Fakultas Ekonomi Universitas Pamulang

Email: abdimasjurnal.unpam@ gmail.com Telp: (021) 741-2566 perusahaan demi mencapai tujuan yang telah ditentukan.

Manajemen SDM sangat perperan penting untuk mengatur pengelolaan SDM dan sumberdaya perusahaan agar memberikan hasil maksimal dan memiliki loyalitas tinggi. Selain itu juga akan memiliki profesionalitas terbaik yang dapat diandalkan untuk mencapai tujuan dan sasaran perusahaan

Dalam jangka panjang, perusahan melalui manajemen sumberdaya manusia akan diarahkan untuk :

a. Memberikan kesempatan sumber daya manusia untuk berkembang menjadi pribadi yang berkualitas dan memiliki daya saing yang tinggi. Selain untuk kebaikan perusahaan juga untuk kebaikan perorangan itu sendiri.

b. Memperkuat produk unggulan di setiap unit kerja untuk menuju keunggulan kompetitif dengan membangun keterkaitan sistem produksi, distribusi, dan pelayanan di dalam perusahaan.

c. Meningkatkan penguasaan,
pemanfaatan, dan penciptaan
pengetahuan

d. Dapat membangun peralatan produksi yang maju dan canggih

e. Melakukan reformasi manajemen administrasi secara sistematis dan terintegrasi agar tujuan perusahaan dapat tercapai dengan baik.

Fungsi HR tersebut adalah

a. Seleksi dan Rekrutmen,

b. Pelatihan dan Pengembangan

(Training and Development),

c. Compensation and Benefit

(Compensation and Benefit),

d. Manajemen Kinerja (Performance Management),

e. Perencanaan Karir (Career Planning),

f. Hubungan Karyawan (Employee Relations),

g. Separation Management, dan

h. Personnel Administration and HRIS.
Budaya perusahaan merupakan nilai atau asumsi dasar yang membentuk pola pikir atau cara pandang kita dalam melihat sesuatu atau melakukan tindakan.

Dampak Gejala Perusahaan Terhadap Daya Guna Organisasi dan Kepuasan Indivindu

a. Budaya perusahaan terhadap strategi, penerapan strategi baru yang kurang atau tidak sejalan dengan asumsi pertama yang biasanya dilandasi visi dan misi organisasi.

b. Kegagalan dalam mengadakan merger atau akuisisi atau diversifikasi karena tidak sejalan dengan pola pikir, nilai, perilaku dan lain-lain.

c. Kegagalan dalam melakukan keterpaduan teknologi baru yang teknologinya belum dapat diterima dalam budaya usaha atau belum dapat dicerna seperti yang seharusnya.

d. Konflik antar unit atau kelompok dalam organisasi disebabkan terjadinya perbedaan persepsi atau pelaksana nilai, perilaku, kebiasaan dan sebagainya.

e. Pertemuan yang tidak berdaya guna dan/atau putusnya komunikasi yang disebabkan terjadinya salah pengertian, penghargaan dan nilainilai yang berbeda dan lain sebagainya.

f. Kegagalan sosialisasi budaya perusahaan dapat menyebabkan kegagalan koordinasi dan intergrasi kegiatan. Kegagalan ini dapat merupakan kegagalan dalam mensosialisasikan ide, prosedur kerja dan teknologi baru yang berbeda dari nilai-nilai dan tradisi yang ada dan sebagainya

g. Akibat budaya perusahaan dapat juga mempengaruhi produktivitas di sebabkan nilai atau kebiasaan kerja yang berbeda.pemberian nilai atau imbalan terhadap personil yang lebih senior atau yang telah lama bekerja sebagai karyawan tetap tanpa memperhatikan produktivitas dan prestasi kerja akan menghambat dan 


\section{JURNAL ABDIMAS

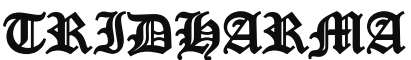

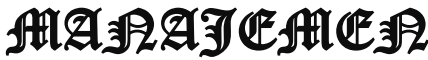

P-ISSN 2615-6849, E-ISSN 2716-070X

Jurnal ABDIMAS Vol. 1,No.2, Mei 2020,Hal(33-41)

@ Prodi Manajemen Fakultas Ekonomi Universitas Pamulang

Email: abdimasjurnal.unpam@ gmail.com Telp: (021) 741-2566 menurunkan prestasi kerja individu karyawan produktif.

\section{Proses Tahapan Manajemen Sumber Daya Manusia \\ a.Recruitment (Pengadaan)}

Recruitment disini diartikan pengadaan, yaitu suatu proses kegiatan mengisi formasi yang lowong, mulai dari perencanaan, pengumuman, pelamaran, penyarigan sampai dengan pengangkatan dan penempatan. Pengadaan yang dimaksud disini lebih luas maknanya, karena pengadaan dapat merupakan salah satu upaya dari pemanfaatan. Jadi pengadaan disini adalah upaya penemuan calon dari dalam organisasi maupun dari luar untuk mengisi jabatan yang memerlukan SDM yang berkualitas.

Recruitment from within merupakan bagian dari upaya pemanfatan SDM yang sudah ada, antara lain melalui pemindahan dengan promosi atau tanpa promosi. Untuk pengadaan pekerja dari luar tahapan seleksi memegang peran penting. Seleksi yang dianjurkan bersifat terbuka (open competition) yang didasarkan kepada standar dan mutu yang sifatnya dapat diukur (measurable). Pada seleksi pekerja baru maupun perpindahan baik promosi dan tanpa promosi, harus memperhatikan unsur-unsur antara lain; kemampuan, kompetensi, kecakapan, pengetahuan, keterampilan, sikap dan kepribadian.

Prinsip pemanfaatan SDM yang terbaik adalah prinsip satisfaction yaitu tingkat kepuasan yang dirasakan sendiri oleh pekerja yang menjadi pendorong untuk berprestasi lebih tinggi, sehingga makin bermanfaat bagi organisasi dan pihakpihak lain. Pemanfaatan SDM dapat dilakukan dengan berbagai cara, mulai dari yang paling mudah dan sederhana sampai cara yang paling canggih. Pemanfaatan SDM perlu dimulai dari tahap pengadaan, dengan prinsip the right man on the right job.

\section{b.Maintenance (pemeliharaan)}

Pemeliharaan atau maintenance merupakan tanggung jawab setiap pimpinan. Pemeliharaan SDM yang disertai dengan ganjaran (reward system) akan berpengaruh terhadap jalannya organisasi. Tujuan utama dari pemeliharaan adalah untuk membuat orang yang ada dalam organisasi betah dan bertahan, serta dapat berperan secara optimal. Sumber daya manusia yang tidak terpelihara dan merasa tidak memperoleh ganjaran atau imbalan yang wajar, dapat mendorong pekerja tersebut keluar dari organisasi atau bekerja tidak optimal.

\section{c. Development (pengembangan)}

Sumber daya manusia yang ada didalam suatu organisasi perlu pengembangan sampai pada taraf tertentu sesuai dengan perkembangan organisasi. Apabila organisasi ingin berkembang seyogyanya diikuti oleh pengembangan sumber daya manusia. Pengembangan sumber daya manusia ini dapat dilaksanakan melalui pendidikan dan pelatihan yang berkesinambungan.

\section{d.Pemberhentian}

Pemberhentian adalah fungsi operatif terakhir manajemen sumber daya manusia. Fungsi pemberhentian harus mendapat perhatian yang serius dari manajer SDM karena telah diatur oleh undang-undang dan mengikat bagi perusahaan maupun karyawan. Istilah pemberhentian atau separation, pemisahan adalah putusnya hubungan kerja seseorang dari organisasi (perusahaan) yang disebabkan oleh keinginan karyawan, keinginan organisasi, pensiun, aatau sebabsebab lain yang diatur oleh undangundang.

Hal-hal berikut juga perlu diperhatikan oleh HRD guna memotivasi karyawan yang ada untuk menjadi karyawan yang berpotensi :

1. Sampaikan kepada karyawan bahwa masing-masing mereka adalah istimewa dan memiliki kemapuan yang unik 


\section{JURNAL ABDIMAS

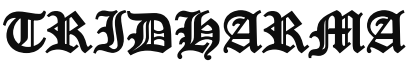

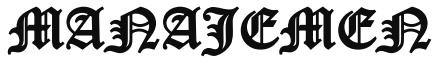

P-ISSN 2615-6849, E-ISSN 2716-070X

Jurnal ABDIMAS Vol. 1,No.2, Mei 2020,Hal(33-41)

@Prodi Manajemen Fakultas Ekonomi Universitas Pamulang

Email: abdimasjurnal.unpam@ gmail.com Telp: (021) 741-2566
2. Tiap-tiap karyawan harus memiliki mimpi bagi pekerjaannya dan langkahlangkah apa yang akan diambil untuk mewujudkan impian tersebut

3. Tiap-tiap atasan harus memandang bahwa bawahannya memiliki potensi sehingga tidak mudah under estimate pada bawahannya.

4. Setiap atasan harus menemukan kelebihan yang dimiliki bawahannya dan turut mengembangkan kelebihan tersebut.

5. Kembangkan pemikiran bahwa tidak ada yang kebetulan sehingga tiap atasan dan bawahan mengembangkan potensi yang ada

\section{METODE PELAKSANAAN}

Metodepelaksanaan pengabdian

1. Ceramah Metode ceramah digunakan untuk menyampaikan penjelasan kepada peserta tentang materi terkait teori SDM yang Potensial untuk kemajuan perusahaan.

2. Tanya Jawab dan Diskusi Metode tanya jawab dilakukan untuk menggali persoalan yang berhubungan dengan materi ceramah. Selain itu juga terkait kesulitan dan permasalahanpermasalahan yang sering dihadapi HR dalam menjalankan fungsi nya. Serta pemberian solusi untuk menyelesaikan masalah yang sering dihadapi.

3. Pendampingan dilakukan pada saat kegiatan berlangsung dan pendampingan pasca pelatihan. Pendampingan pada saat kegiatan berlangsung dilakukan untuk mengetahui dan membantu kesulitan yang dialami peserta. Pendampingan pasca pelatihan dimaksudkan untuk memberikan arahan dan membimbing pengelolaan SDM bagi peserta setelah dilakukan pelatihan. HR PT Sejati Grup menerima pertanyaan dan konsultasi terkait permasalah yang terjadi dalam implementasi teori dan praktek yang melalui media telepon dan pesan singkat. E. Evaluasi Evaluasi dilakukan pada saat proses pelatihan berlangsung. Evaluasi saat proses praktek akan memudahkan pendamping (dosen) untuk memberikan pendampingan agar peserta dapat melakukan pengelolaan SDM dengan baik. Evaluasi proses dilakukan agar dapat langsung mengetahui kesulitan yang dialami peserta.

4. Luaran Hasil pelaksanaan PKM ini akan dirangkum dan dituliskan dalam artikel untuk dipublikasikan dalam jurnal

\section{HASIL DAN PEMBAHASAN}

Pada Hari pertama Pembukaan dan pemaparan konsep Materi - materi SDM yang potensial dengan slide powerpoint yang sudah di buat sehingga memudahkan dalam penyampaian materi kepada karyawan yang di bawakan oleh pa Wahadi Siamto sebagai Narasumber yang ahli di bidang SDM keahlian nya yaitu sebagai dosen SDM, dan juga sebagai Manajer Training di Perusahaan HokaHoka Bento Salah satu Perusahaan yang bergerak di bidang makanan terbesar di Indonesia beliau mempaparkan apa saja yang membuat Sumber Daya Manusia berkualitas dan bagaimana mengetahui signal signal potensi karyawan utk diolah menjadi sumber yang potensial.demi kemajuan perusahaan setelah pemamparan di adakan Tanya jawab dan diskusi.

Pada Hari kedua pemaparan dan pendampingan pembuatan Strategi Strategi SDM oleh Ibu Windy selaku Dosen Sumber Daya Manusia bagaimana menerapkan Strategi yang jitu yang harus di terapkan dalam pengelolaan SDM khususnya pada PT Sejati Grup. Kemudian setelah itu diadakan pendampingan dalam pembentukan flowchartz strategi-strategi yang akan di gunakan PT Sejati Grup dalam langkah berikutnya setelah PKM ini diselenggarakan .

Pada Hari Ketiga pemaparan teoriteori Job Competency dan Penutup oleh ketua PKM kali ini Ibu Nurwita Selaku Dosen Manajemen dan merangkap juga sebagai asesor kompetensi .Menerapkan 


\section{JURNAL ABDIMAS

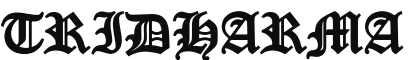

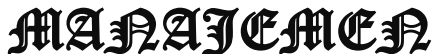

P-ISSN 2615-6849, E-ISSN 2716-070X

Jurnal ABDIMAS Vol. 1,No.2, Mei 2020,Hal(33-41)

@Prodi Manajemen Fakultas Ekonomi Universitas Pamulang

Email: abdimasjurnal.unpam@ gmail.com Telp: (021) 741-2566 dalam bekerja di perlukan kompetensi yang memadai yaitu keseimbangan mulai dari knowledge, skills dan behaviours ketiga unsur ini harus saling melengkapi dan berkesinambungan ini sangat berpengaruh atas kinerja nya kualitas kinerja yang bagus akan menghasilkan tujuan dari suatu perusahaan jika tujuan suatu perusahaan tercapai maka akan mendatangkan laba sehingga laba yang datang akan di pergunakan untuk kemajuan perusahaan baik dan secara intern dan ekstern sehingga menjamin perusahaan tersebut tetap hidup dan beroperasi. Sehingga ada pendampingan pembuatan jadwal pelatihan , pengembangan dan pengujian kompetensi setiap bidang departemen. Evaluasi saat proses praktek akan memudahkan pengabdi untuk memberikan pendampingan agar peserta dapat melakukan sesuai apa yang telah di paparkan. Setelah acara selesai di adakan doa penutup acara PKM ini selesai dan pembagian Cindera Mata yang di bungkus dengan kertas kado serta Acara Poto Bersama dengan 6 karyawan HRD PT Sejati Grup.

Faktor pendukung dalam pelaksanaan kegiatan pelatihan dalam rangka pengabdian pada masyarakat ini adalah:

1. Semangat antusias yang tinggi oleh karyawan HR di PT Sejati Grup menyambut PKM ini.

2. Respon yang positif terhadap pelatihan yang disampaikan pihak PT Sejati Grup.

3. Terjalinnya kerjasama yang baik antara penyelanggara dengan PT Sejati Grup.

4. Terjalinnya komunikasi yang efektif antara pengabdi PKM dengan peserta pada saat koordinasi sebelum acara dilaksanakan

\section{KESIMPULAN DAN SARAN \\ Kesimpulan}

Kegiatan PKM telah dilaksanakan dengan lancar dan baik serta telah memberikan pengetahuan dan keterampilan dalam bidang SDM untuk Kemajuan Perusahaan . Berdasarkan pembahasan di atas maka dapat disimpulkan bahwa manajemen SDM merupakan suatu proses yang meliputi serangkaian tindakan, dimana unsur-unsur dan fungsi- fungsi manajemen dipekerjakan se-efisien dan efektif mungkin dengan bantuan Karyawan sebagai Sumber Daya Manusia yang bertujuan untuk mencapai goals dan sasaran yang telah ditentukan sesuai dengan kebutuhan akan adanya kemajuan perusahaan serta berdasarkan atau melebihi standar kompetensi kerja yang telah ditetapkan mulai dari input, proses, sampai pada out- put nya.

\section{Saran}

Adapun saran pada PKM ini adalah sebagai berikut:

1. Sejati Teknologi belum melakukan pendekatan secara menyeluruh kepada pemerintah karena PT Sejati Group bertindak hal nya supplier sehingga dalam kualitas sumber daya manusia di bidang pemasaran masih belum di andalkan sehingga harus disarankan mengikuti pelatihan - Pelatihan yang di adakan oleh pemerintah maupun swasta.

2. Untuk mewujudkan SDM yang potensial dan kompeten di bidangnya perlu di adakan latihan dan pengembangan sesuai jadwal yang sudah di tentukan.

3. Perlu mengadakan intensitas training pengembangan $\mathrm{SDM} /$ pengurus yang telah terjadwal dan mengadakan evaluasi secara berkala.

4. Jika akan melakukan PKM di PT Sejati Grup bisa langsung $\mathrm{k}$ outletoutlet usaha nya Karena jika di kantor pusat area nya lebih privasi akan adanya public. 


\section{JURNAL ABDIMAS

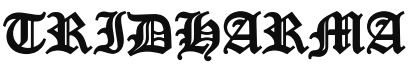

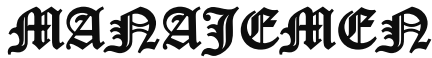

P-ISSN 2615-6849, E-ISSN 2716-070X

Jurnal ABDIMAS Vol. 1,No.2, Mei 2020,Hal(33-41)

@Prodi Manajemen Fakultas Ekonomi Universitas Pamulang

Email: abdimasjurnal.unpam@gmail.com Telp: (021) 741-2566
DAFTAR PUSTAKA

Dessler, Gery. 2009. Manajemen Sumber Daya Manusia. Edisi ke-10. Jakarta Barat. PT. INDEKS.

Devito, joseph

2013.KomunikasiAntarManusia.

Profesional Books.

Hasibuan, Malayu S. P., 2009. ManajemenSumberDayaManusia.

Jakarta: BumiAksara.

Hakim, Lulman. 2015. Perilaku Organisasi. Sukoharjo: CV. Jamine

Krisnaldy,,Gos Ishak (2018). Manajemen wajtu dalam penggunaan gadget dan alat komunikasi era saat ini Jurnal Pengabdian Dharma Laksana, 1(2), 150-160.

Pasaribu, V. L. D., Agrasadya, A., Shabrina, N., \& Krisnaldy, K. (2020). MENJADI ENTERPRENEUR MUDA YANG MEMILIKI JIWA LEADERSHIP UNTUK MENGHADAPI MASA

DEPAN. Abdi Laksana, 1(1).

Pasaribu, V. L. D., Elburdah, R. P., Sudarso, E., \& Fauziah, G. (2020). PENGGUNAAN MANAJEMEN WAKTU TERHADAP PENINGKATAN PRESTASI BELAJAR DI SMP ARAISIYAH. Jurnal ABDIMAS, 1(1).

Pasaribu, V. L. D., Susanti, F., \& Hartuti, E. T. K. (2019). MEMOTIVASI SISWA DAN SISWI SMK LETRIS INDONESIA DI DALAM MENENTUKAN PILIHAN UNTUK MELANJUTKAN PENDIDIKAN ATAU BEKERJA SETELAH LULUS SEKOLAH. Jurnal Pengabdian Dharma Laksana, 1(2), 161172.

Qurbani, D., Oktrima, B., \& Tanjung, A. W. (2019). MENDIDIK DAN MENGAJARKAN ANAK UNTUK MENGENAL ALLAH PADA USIA DINI DENGAN METODE STORY

A.
TELLING DI TK AL-HIDAYAH PAMULANG, TANGERANG SELATAN. Jurnal Pengabdian Dharma Laksana, 1(2), 228-239.

https://ekonomi.bisnis.com/read/20190806/ 12/1132979/mencari-cara-kerek-kualitas$\underline{\text { sdm-di-era-revolusi-industri-4.0 }}$

http://sejatigroup.com/

http://bbpp-

lembang.info/index.php/arsip/artikel/artike 1-pertanian/558-jaminan-keamananpangan-dengan-sistem-haccp-hazardanalysis-critical-control-point/

https://teknologi.id/insight/keterampilanyang-perlu-kamu-miliki-untukmenghadapi-revolusi-industri-4-0/

\section{DOKUMENTASIFOTO KEGIATAN}
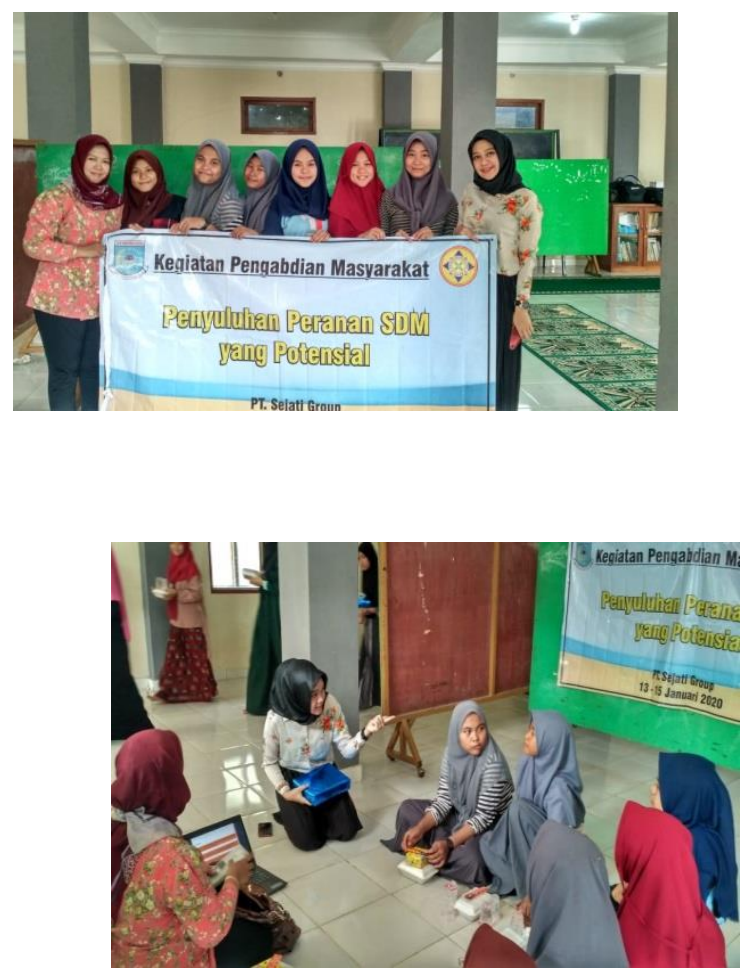